\title{
Irrigant Dosage Form
}

National Cancer Institute

\section{Source}

National Cancer Institute. Irrigant Dosage Form. NCI Thesaurus. Code C42947.

A solution or suspension used to bathe or flush open wounds or body cavities. 